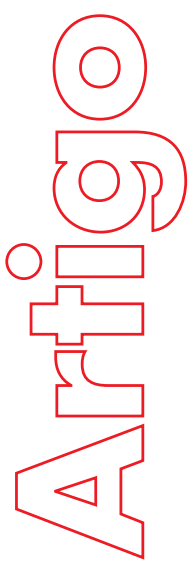

Revista

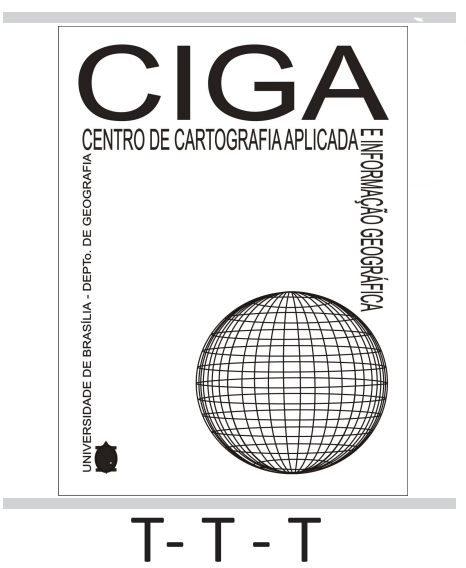

Revista Eletrônica: Tempo - Técnica - Território, V.11, N.1 (2020), 87:103 ISSN: 2177-4366

\section{ANÁLISE DAS ABORDAGENS UTILIZADAS EM LIVROS DIDÁTICOS DO ENSINO MEDIO RELACIONADAS AO HISTÓRICO AFROBRASILEIRO E PRATICAS DE ORIGENS AFRICANAS}

\section{Yara da Silva Barcellos}

p. $87-103$

Como citar este artigo:

Barcellos, Y. S.

ANÁLISE DAS ABORDAGENS UTILIZADAS EM LIVROS DIDÁTICOS DO ENSINO MÉDIO RELACIONADAS AO HISTÓRICO AFROBRASILEIRO E PRÁTICAS DE ORIGENS AFRICANAS - Revista Eletrônica: Tempo -

Técnica - Território, v.11, n.1 (2020),p.87:103 ISSN: 2177-4366.

Disponível em: http://periodicos.unb.br/index.php/ciga/

Este obra está licenciado com uma Licença Creative Commons Atribuição - Não Comercial 4.0 Internacional. 


\title{
ANÁLISE DAS ABORDAGENS UTILIZADAS EM LIVROS DIDÁTICOS DO ENSINO MÉDIO RELACIONADAS AO HISTÓRICO AFROBRASILEIRO E PRÁTICAS DE ORIGENS AFRICANAS
}

\author{
Yara da Silva Barcellos \\ Graduando em Geografia pela Universidade de Brasília, Disciplina GEOAFRO - 1 Semestre \\ 2019. E-mail: yaarabarcellos@gmail.com
}

\begin{abstract}
RESUMO: - Os livros didáticos tem o papel de ser um norte para os professores e um material de apoio para os alunos e por isso existe a necessidade de analisá-los antes de serem trabalhados em sala de aula. A abordagem sobre afrodescendentes e áfrica em sala de aula e em livros didáticos ainda deixam a desejar, mas a educação é a esperança que se tem de possíveis mudanças na estrutura racista que existe. É preciso acreditar na educação e na leitura como uma prática social. Objetivo - Analisar o livro didático Território e sociedade no mundo globalizado de geografia, criticar como os autores se posicionam a respeito da áfrica e do brasil africano e finalmente desenvolver metodologias e práticas de ensino para abordagem do assunto em sala de aula, com recorte para as turmas de terceiro ano do ensino médio. Metodologia - O método utilizado para a escolha do livro foi através da análise de outros 3 livros destinados o mesmo período do ensino médio (terceiro ano), utilizar a ferramenta CTRL F para visualizar quantas menções existiam sobre o presente assunto em todo livro e análise de correntes geográficas e conceitos através da leitura do livro. Resultados - Foi possível encontrar 67 menções com as palavras “'África, pretos e afrodescentes', O livro possui uma abordagem descritiva crítica, a qual apresenta muito bem os dados e os assuntos, sem forma estereotipada a respeito dessa população em questão. Conclusão - O livro é importante porque segue uma linha de conceitos, história e atualidade, sendo um forte alinhado para o professor em sala de aula, inclusive pelas propostas de atividade que são apresentadas. A sala de aula precisa ser um lugar a ser construído em conjunto e tratado como um espaço político. As medidas sugeridas para começar a falar sobre política em sala de aula, o desenvolvimento de projetos e maneiras diferentes para que assuntos como racismo, África e ancestralidade sejam discutidos em sala de aula e com embasamento real, sejam por meios de debates, sejam por meios de documentários ou por meio de materiais criados pelos próprios alunos. Tendo a implantação de um programa de qualidade e inseri-lo no projeto político-pedagógico.
\end{abstract}

Palavras-chave: Livro didático; Geografia; Alunos; África; Afro-Brasileiro; Prática Social

ABSTRACT - Textbooks have the role of being a north for teachers and a support material for students and so there is a need to analyze them before they are worked in the classroom. The approach to African descendants and Africa in the classroom and in textbooks still leaves something to be desired, but education is the hope for possible changes in the racist structure that exists. We must believe in education and reading as a social practice. Objective - To 
analyze the textbook Territory and society in the globalized world of geography, to criticize how authors position themselves about Africa and African Brazil and finally to develop teaching methodologies and practices for addressing the subject in the classroom, with clipping for the third year high school classes. Methodology - The method used to choose the book was through the analysis of 3 other books destined for the same period of high school (third year), use the CTRL F tool to visualize how many mentions there were about this subject in every book and analysis of geographical currents and concepts by reading the book. Results - It was possible to find 67 mentions with the words 'Africa', Blacks and Afrodescents', The book has a critical descriptive approach, which presents very well the data and the subjects, without stereotyped form regarding this population in question. Conclusion - The book is important because it follows a line of concepts, history and actuality, being a strong aligned for the teacher in the classroom, including by the activity proposals that are presented. The classroom needs to be a place to be built together and treated as a political space. The suggested measures to start talking about classroom politics, the development of different projects and ways for subjects such as racism, Africa and ancestry to be discussed in the classroom and with real grounding, whether by means of debates, either through documentaries or through materials created by the students themselves. Having the implementation of a quality program and insert it in the political-pedagogical project.

Keywords: Textbook; Geography; Students; Africa; Afro-Brazilian; Social Practice.

\section{INTRODUÇÃO}

A riqueza de temas a serem tratados em sala de aula advém de uma diversidade de espaços, realidades, histórias e paisagens que formam o abundoso painel diário dos povos e dos lugares. Os assuntos que são passíveis de polêmica normalmente são evitados ou trabalhados de forma bem rápida nas salas, como por exemplo, quando se fala de racismo. Mas será que os professores e educadores de Geografia pensam que eles têm o papel de apresentar o mundo e possivelmente fazer um aluno se encontrar nele? Sem vivência não tem pertencimento. Para isso é importante acabar com as visões estereotipadas da áfrica, os africanos e os afrodescendentes que além disso ainda existe uma onde de desconhecimento de boa parte da população brasileira sobre sua ancestralidade, contudo contribuir para o romper da perpetuação de desigualdades e preconceitos que historicamente atinge a população indígena e afrodescendente, esses avanços são mais do que necessários.

A África e os afrodescendentes são uma parte importante da formação da população mundial e do Brasil. Alguns livros ainda retratam os negros de forma esteriotipada e falando apenas de racismos sofridos, os diminuindo apenas a isso. Mas isso é reflexo de um capitalismo 
que se sustentou com o racismo, com a forma que o estado se comporta e como a elite branca ainda lida com esse assunto.

Para isso, existe a necessidade de que a educação seja tratada mais do que nunca como uma prática política e social, pois a educação ainda tem o papel de formar caráter e a cidadania de uma pessoa e o livro didático é um forte aliado a isso.

No livro ''Ensino de Geografia, novos temas para a geografia escolar'” (2019), os autores se posicionam a favor dos temas tratados em sala de aula estarem alinhados com a nova agenda da Geografia mundial e brasileira, juntamente às necessidades do mundo. Nesse mesmo livro é citado o relatório para a UNESCO da Comissão Internacional sobre Educação para o século XXI,

para poder dar resposta ao conjunto de suas missões, a educação deve organizar-se em torno de quatro aprendizagens fundamentais que, ao longo de toda vida, serão de algum modo para cada indivíduo, os pilares do conhecimento: aprender a conhecer, isto é adquirir os instrumentos da compreensão; aprender a fazer, para poder agir sobre o meio envolvente; aprender a viver juntos, a fim de participar e cooperar com os outros em todas as atividades humanas; finalmente aprender a ser, via essencial que integra as três precedentes.

Por isso, faz-se necessário pesquisas desse cunho no meio da educação, e por meio da análise do livro “'Território e Sociedade no Mundo Globalizado', será avaliado a boa aplicabilidade dele em sala de aula, ou a não recomendação.

\section{FICHA TÉCNICA}

O livro escolhido para análise no presente artigo é '’Território e Sociedade no mundo globalizado", é o terceiro volume desta série de livros para Ensino Médio, ou seja, para alunos do terceiro ano, sendo a terceira edição do livro apresentado. Contando com três autores, Elian Alabi Lucci, Anselmo Lázaro Branco e Cláudio Mendonça, foi publicado em São Paulo no ano de 2016. O livro possui 11 capítulos os quais são divididos em 4 unidades, sendo a unidade 1 sobre etnia, diversidade cultura e conflitos; a unidade 2 sobre espaço geográfico e urbanização; a unidade 3 sobre espaço, sociedade e economia e a unidade 4 sobre perspectivas e regionalização do Brasil. Possuindo 2 versões, sendo o manual do professor e o livro didático, a primeira opção foi a escolhida para a presente análise. 


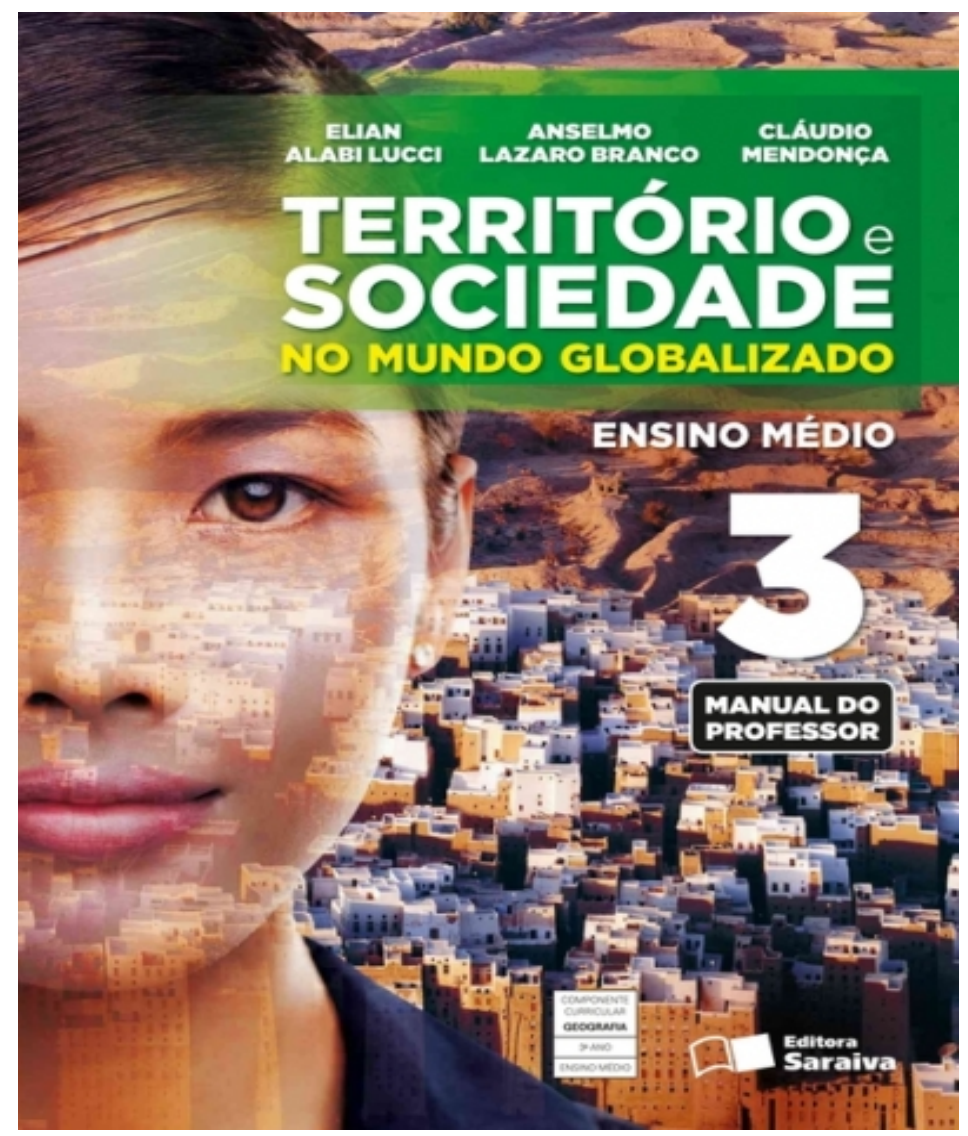

Imagem 1: Capa do livro didático/manual do professor '’Território e sociedade no mundo globalizado’’. Ensino médio, volume 3 (2016). Disponível em: https://www.yumpu.com/pt/document/view/63151632/geografia-territorio-e-sociedade-nomundo-globalizado-volume-3-2016

\section{CONCEPÇÃO DE GEOGRAFIA}

O livro segue uma concepção geográfica bem explícita de teor descritivo com caráter crítico, pois diversos dados são apresentados, mas levantam questionamentos e fazem com que os alunos busquem mais e analisem de fato os dados levantados em questão.

Em uma sociedade que pouco conhece suas origens e que é muito possível de ser superado através da educação. E o viés crítico no livro vem para somar e '’facilitar’' caminhos, inclusive porque a geografia tem um papel importantíssimo nisso, de acordo com Iná Elias de Castro (2019) A geografia é a disciplina quem tem o mérito de revelar ao estudante o seu lugar no mundo. E não é diferente quando falamos de história e ancestralidade, a geografia e a educação tem o mérito de revelar e fazer entendido da onde viemos e quem somos por meio de pesquisas e análises. 
Já no início do livro, no capítulo 1 pode-se perceber como essa concepção geográfica, quando eles trazem os dados, a análise dos dados e a crítica (e ainda dá outras opções como filmes para que os alunos se aprofundem no assunto).

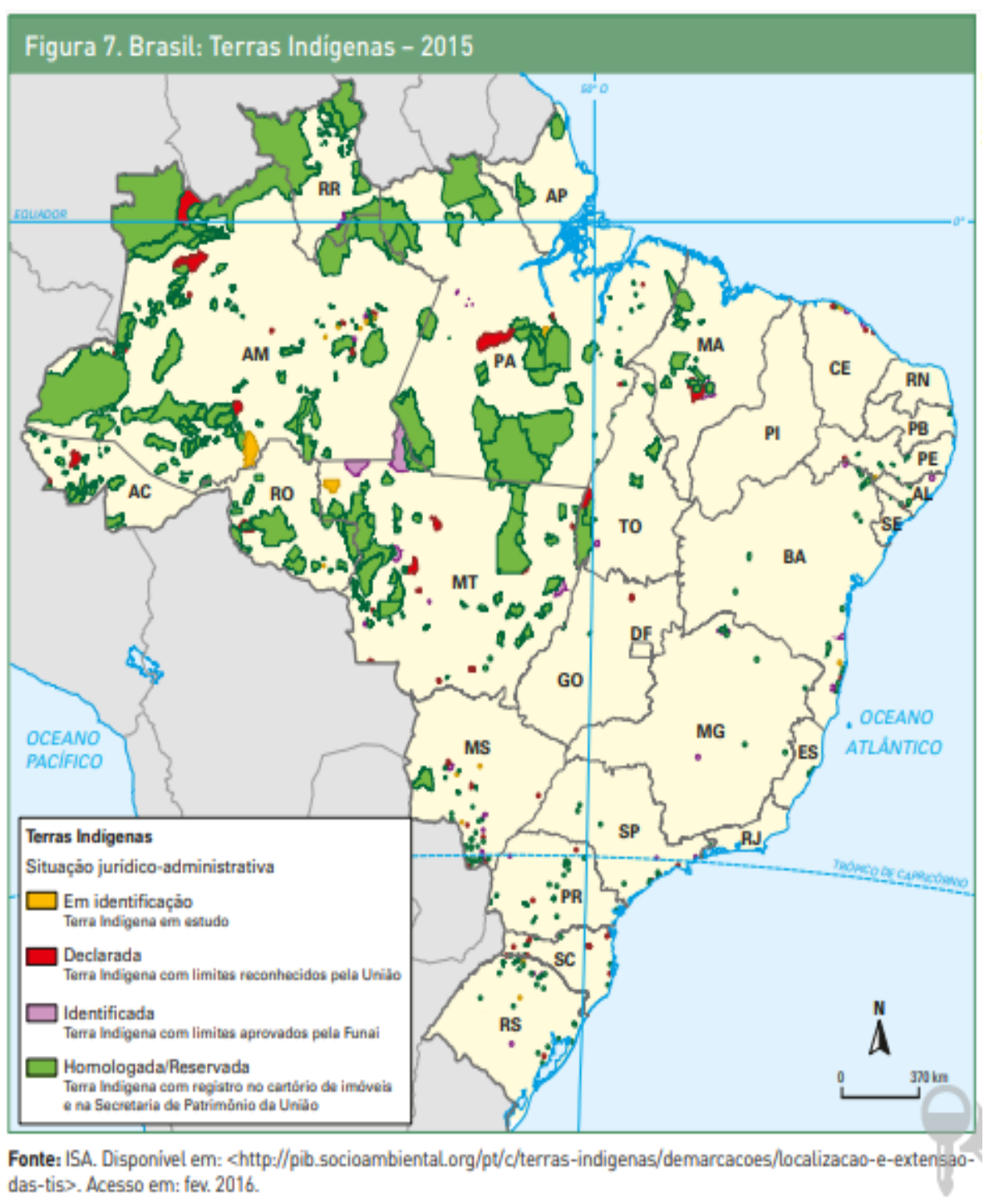

Imagem 2: Brasil: Terras Indígenas - 2015. Disponível em:

https://www.yumpu.com/pt/document/view/63151632/geografia-territorio-e-sociedade-nomundo-globalizado-volume-3-2016.

Além de que em todo final de capítulo existe uma parte 'extra' chamada compreensão e análise, que conta com imagens, dados e gráficos e como eles podem ser interpretados e aplicados em questões do ENEM. 


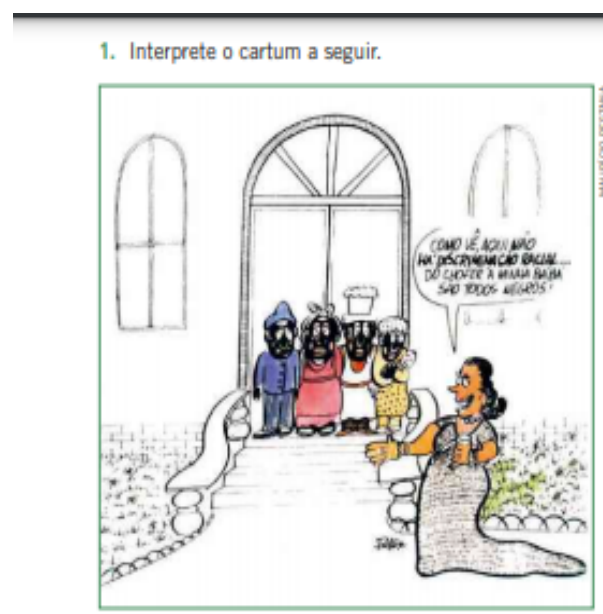

PESTANA Mauricio. Racista, aul? De jaito nomhum_. SSa Paula: Escala, 2. Observe os gráficos.

Brasil: rendimento familiar per capita das pessoas de 10 ou mais anos de idade entre os $10 \%$ mais pobres e $01 \%$ mais rico, em
relação as total de pessoas, por cor ou raça ${ }^{*}-2004 / 2013$

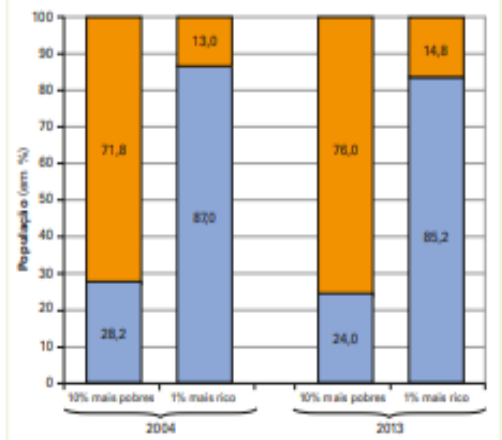

$\square$ Branca $\square$ Prota ou parda

Fente: Sintose dos intikadores Socisis. Fivo de Janeire: 18GE, 2014, p. 153
3. A tabela a seguir apresenta a evolução da populaçấo amerindia no Brasil, entre 1500 e 2010 . Observe os dados e explique as alteraçôes no inicio da colonizaçăo e nas últimas décadas.

\begin{tabular}{|c|c|}
\hline $\begin{array}{c}\text { Brasil: evoluçāo da populaçäo amerindia - } \\
1500-2010\end{array}$ \\
\hline Ano & Amerindios \\
\hline 1500 & $4.500 .000^{*}$ \\
\hline 1890 & $460.000^{*}$ \\
\hline 1990 & 280.000 \\
\hline 2000 & 134.100 \\
\hline 2010 & 817.900 \\
\hline
\end{tabular}

"Estimativa.

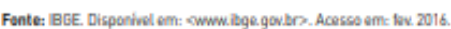

\section{ENEM E VESTIBULARES}

- (Enem 2014)

"Parecer CNE/CP n. 3/2004, que instituiu as Diretrizes Curriculares Nacionais para a Educação das Relações Êtnico-Raciais e para o Ensino de História e Cultura Afro-Brasileira e Africana. Procura-se oferecer uma resposta, entre outras, na área da educaçẫo, à demanda da população afrodescendente, no sentido de politicas de açôes afirmativas. Propõe a divulgaçẫo e a produçẫo de conhecimentos, a formaçẫo de atitudes, posturas que eduquem cidadãos orgulhosos de seu pertencimento étnico-racial - descendentes de africanos, povos indigenas, descendentes de europeus, de asiáticos - para interagirem na construção de uma naçẫo democrática, em que todos igualmente tenhami seus direitos garantidos."

BRASIL. Conselho Nacional de Educacha. Disponivétemestwir. semesporg brs. Acesso em: 21 nov. 2013 (adaptado).

A orientação adotada por esse parecer fündament uma politica pública e associa o principio da inclusăo social a

Imagem 3: Compreensão e análise do capítulo. Disponível em:

https://www.yumpu.com/pt/document/view/63151632/geografia-territorio-e-sociedade-nomundo-globalizado-volume-3-2016.

\section{ESPAÇO GEOGRÁFICO}

O conceito de espaço geográfico aparece não somente em um lugar nesse livro, mas já na apresentação, os autores já iniciam a parte de apresentação do livro apresentando a tecnologia como principal definidor e modificador do espaço geográfico, além de ter a diversidade de etnias e coexistência entre os povos como um marco nas modificações do espaço geográfico.

No capítulo 4, são apresentados alguns conceitos que compõem o espaço geográfico, mas o principal deles é o conceito de lugar, que possui significados, sentimentos e experiências, ou seja, o lugar é definido como um espaço necessariamente físico, o qual existe algum tipo de convivência. Sabendo que a formação social de todos indivíduos está totalmente ligada à formação espacial destes, podemos falar sobre categorias geográficas tais como território e 
lugar. Dentre as inúmeras aproximações que podemos fazer destas categorias na educação geográfica fica em evidência o Lugar como dimensão espacial do cotidiano, daquilo que é vivido/percebido e o Território como dimensão política do espaço conectada com outras óticas, principalmente a ótica econômica e simbólica (SANTOS 1999). O conceito mostra que para ter um lugar, precisa existir um sentimento de pertencimento, ou seja, viver para pertencer.

\section{QUESTÕES ÉTNICO-RACIAIS NO BRASIL}

O livro aborda em diversos capítulos sobre questões étnico-raciais no brasil e diferentemente de outros livros, trata o assunto com seriedade e respeito. Sendo um livro que traz conceitos, história e atualidade.

O Capítulo 1 'etnia, diversidade cultural e conflitos'” já se inicia com uma contextualização com o quadrinho '’racista, eu?!', onde o quadrinho aborda temas não só racial, mas de intolerância religiosa e de outros tipos de descriminação, que tinha como finalidade incentivar uma reflexão entre professores, com base em problemáticas cotidianas de um cidadão europeu.
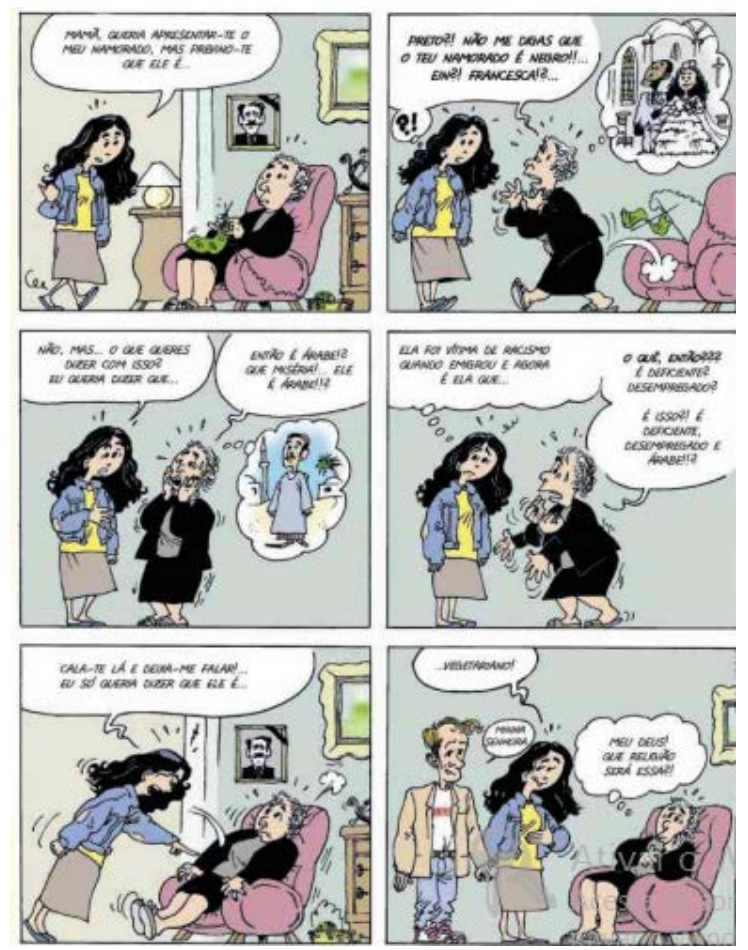

Imagem 4: Racista, eu!? Luxemburgo. Serviço de Publicações Oficiais das Comunidades Europeias, 1998. p. 11. Disponível em:

https://www.yumpu.com/pt/document/view/63151632/geografia-territorio-e-sociedade-nomundo-globalizado-volume-3-2016. 
Logo após essa introdução temos uma abordagem sobre diversidade cultural, onde inicia-se contando o histórico da sociedade humana e que as pessoas se identificam necessariamente com os clãs e as aldeias nas quais estavam inseridas, existindo uma possibilidade quase nula de ter contato com outros tipos de culturas e costumes. O que levou cada grupo específico a criar seus mecanismos de defesa e um modo de sobrevivência, mas ao decorrer dos anos tanto choques quanto assimilações foram acontecendo.

Quando é apontado o choque cultural, entra-se no assunto de etnia, sendo um dos principais e mais importantes elementos do processo de construção da identidade de um grupo sociocultural. Ou seja, um grupo étnico reúne pessoas que compartilham laços, sejam biológicos ou culturais (podendo ser os dois), fazendo assim com que exista a ancestralidade comum, as formas de organizar a sociedade, a língua e até mesmo práticas religiosas.

\subsection{RAÇA E DESIGUALDADE}

Quando os portugueses pisaram nessas terras, já existia um "mosaico étnico” formado por diferentes comunidades de povos indígenas e com o início do processo de colonização no século XVI, os portugueses começaram a exterminar os povos nativos, a querer dominá-los e junto a eles somaram-se os africanos que estavam sendo trazidos à força para trabalhar como escravos. O livro aponta a chegada voluntária, vulgo imigração dos grupos europeus e asiáticos, para trabalhar no Brasil em lavouras de café e que viriam também a adentrar nas indústrias. Fazendo com que o Brasil seja formado por tantos grupos étnicos distintos, que levou a passarmos por um processo de miscigenação. 


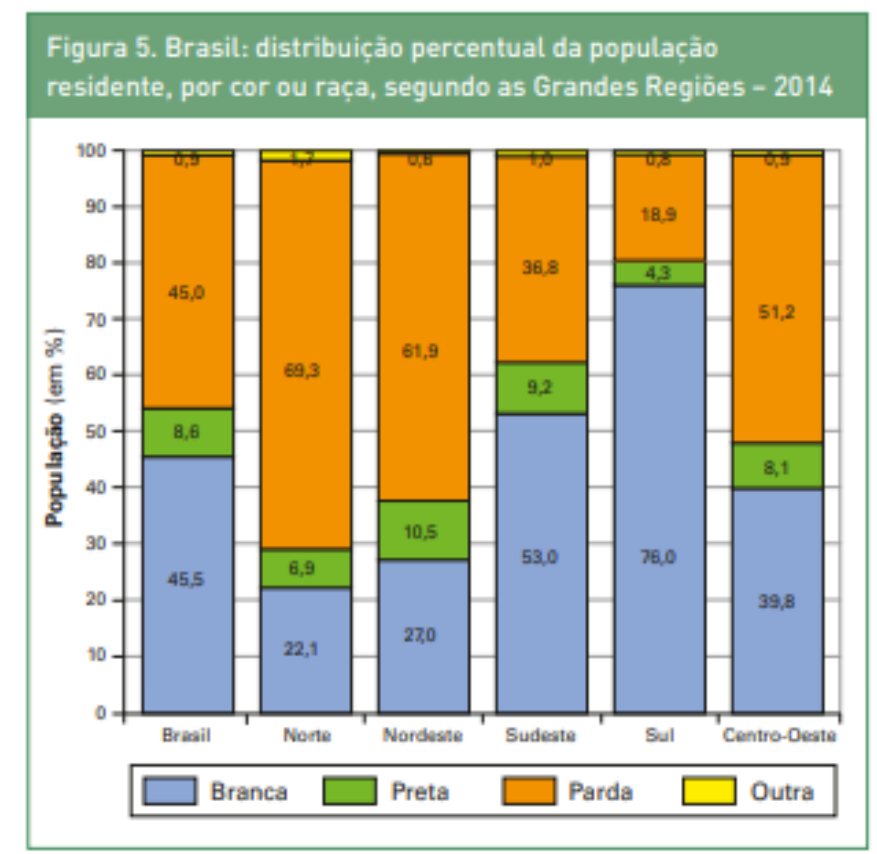

Fonte: IBGE. Pnad 2014. Disponivel em: <www.ibge.gov.br>. Acesso em: nov. 2015.

Imagem 5: . Brasil: distribuição percentual da população residente, por cor ou raça, segundo as Grandes Regiões - 2014. Disponível em:

https://www.yumpu.com/pt/document/view/63151632/geografia-territorio-e-sociedade-nomundo-globalizado-volume-3-2016.

Na página 24 entra-se em uma parte exclusiva do livro e deste capítulo em específico para falar sobre os afrodescentes. Falando sobre a origem dos africanos que foram trazidos à força para trabalhar como escravos, e fala detalhadamente quantos eram e o que faziam aqui. Relata muito bem como foi o processo de abolição da escravatura, sendo o Brasil o último país ocidental a aderir a abolição e a realidade dos afrobrasileiros e africanos desde o fim da escravidão (sendo uma falta libertação) até os dias de hoje (com recorte de tempo, pensando que o livro foi publicado em 2016). O livro traz uns dados importantes também a respeito da quantidade de negros existentes no Brasil, do IBGE de 2014, onde afirmam que o Brasil é o país que mais tem população negra fora da África. E que mesmo depois de muitos anos, os afrodescentes passam por diversas dificuldades, sendo consequências do racismo (retratado no livro como preconceito), desigualdade e exclusão social.

O livro propõe uma atividade de crítica importante, onde os alunos precisam apontar fatores históricos e criticar o cartum abaixo. 


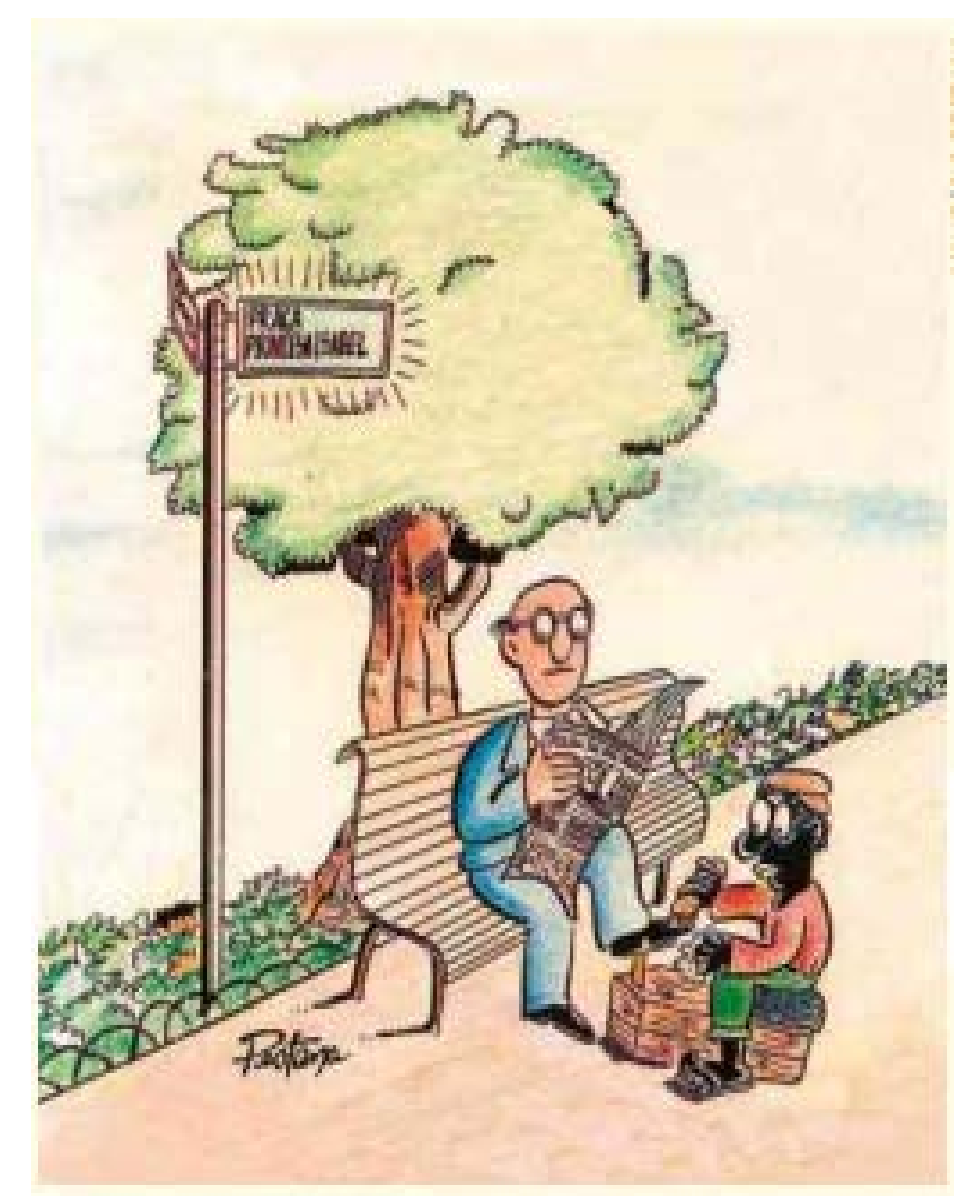

Imagem 6: PESTANA, Maurício. Racista Eu!? De jeito nenhum... São Paulo: Escala, 2001. p. 22. Página 25 do livro

TERRITÓRIO E SOCIEDADE NO MUNDO GLOBALIZADO: ENSINO MÉDIO VOLUME 3 (2016). Disponível em:

https://www.yumpu.com/pt/document/view/63151632/geografia-territorio-e-sociedade-nomundo-globalizado-volume-3-2016.

Logo após a atividade citada anteriormente, cita-se o racismo no Brasil, que relata que a origem étnica dificulta tudo para um negro no Brasil, inclusive a inserção no mercado de trabalho, sendo os afrodescendentes os mais atingidos pelo desemprego e os que estão empregados ocupam atividades que não necessitam de alta qualidifcação. E apontam as periferias, as problemáticas de serviços básicos, como saúde, saneamento, lazer e etc.

O livro traz uma análise a respeito dos salários recebidos pelos afrodescentes, e traz uma análise muito importante sobre isso. 


\begin{tabular}{|c|c|c|c|}
\hline \multicolumn{4}{|c|}{ Brasil: desigualdade segundo a cor da pele - 2014} \\
\hline & Brasil & Brancos & Negros* \\
\hline População total & 203,2 milhões** & $45,5 \%$ & $53,6 \%$ \\
\hline $\begin{array}{l}\text { Proporção da população de } 10 \text { anos ou mais de } \\
\text { idade entre os } 10 \% \text { com menores rendimentos. }\end{array}$ & - & $22,8 \%$ & $76,0 \%$ \\
\hline $\begin{array}{l}\text { Proporção da população de } 10 \text { anos ou mais de } \\
\text { idade entre o } 1 \% \text { com maiores rendimentos. }\end{array}$ & - & $79,6 \%$ & $17,4 \%$ \\
\hline $\begin{array}{l}\text { Proporção dos estudantes de } 18 \text { a } 24 \text { anos de } \\
\text { idade que frequentam o ensino superior. }\end{array}$ & $58,5 \%$ & $71,4 \%$ & $45,5 \%$ \\
\hline $\begin{array}{l}\text { Proporção da população com } 16 \text { anos ou mais } \\
\text { idade ocupada em emprego informal. }\end{array}$ & $42,3 \%$ & $35,3 \%$ & $48,4 \%$ \\
\hline
\end{tabular}

Fonter IBGE. Sintese de Indicadores Sociais. Uma análise das condições de vida da população brasileira 2015. Disponivel em: <http://biblioteca.ibge.gov.br/>. Acesso em: fev. 2016.

Imagem 7: Brasil: desigualdade segundo a cor da pele - 2014. Página 26 do livro TERRITÓRIO E SOCIEDADE NO MUNDO GLOBALIZADO: ENSINO MÉDIO VOLUME 3 (2016).

Algo interesse de se observar nos gráficos apresentados no livro é que eles não apontam o preto e o pardo de formas separadas, ou seja, eles somam os resultados dos dois para apresentar e montar as tabelas.

O livro aponta que existiu sim uma raiz histórica, que foi marcada por quase quatro séculos de escravidão, afirma que a situação ainda se mantem em função da deficiencia da educação pública, do dificil acesso a novas tecnologias (a população mais pobre) e etc, e que por esses motivos, acaba sendo negado aos povos tradicionais (tanto afrodescendentes quanto indigenas) o fato mínimo de direitos e oportunidades iguais. Aponta a constituição brasileira como crime e critica o fato de ser necessário ter algum tipo de testemunha para que uma ocorrência seja registrada e aponta também o fato de que existem coisas que são muito difíceis de provar que é uma prática racista, mas que é muito evidente, como negar uma vaga de emprego em virtude da cor da pele. Os autores tratam as ações afirmativas como necessárias, inclusive por virtude das diferenças socioeconômicas e que são super visíveis simplesmente pela cor da pele. 


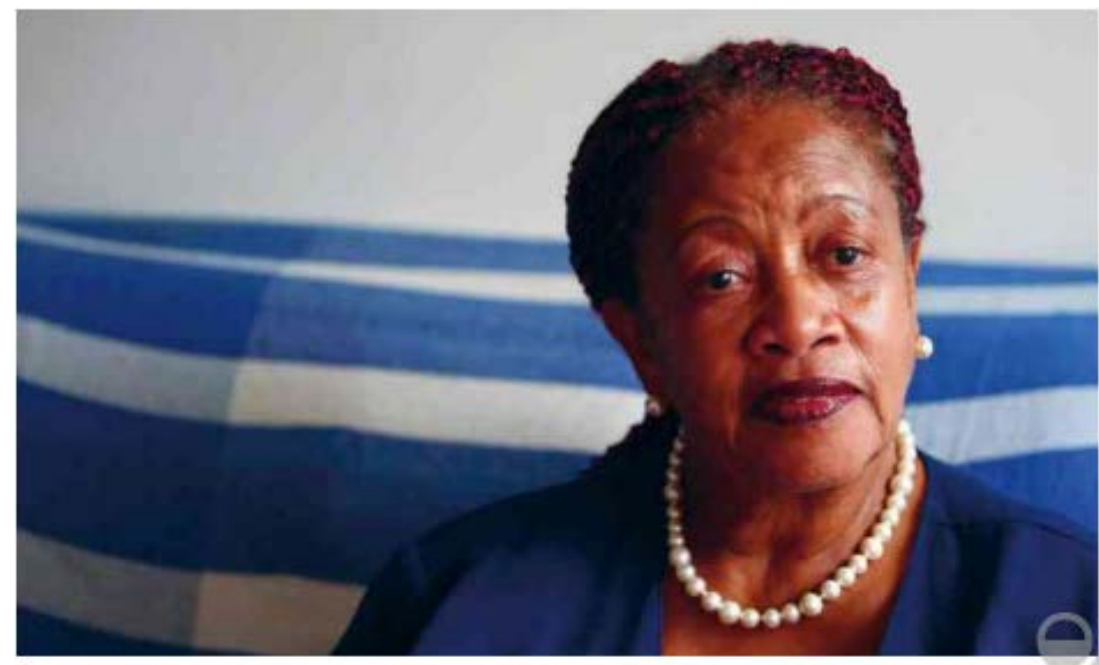

Imagem 8: A baiana Luislinda Valois Santos, primeira juíza afrodescendente do Brasil e também proferiu a primeira sentença contra racismo, responsável pela condenação de um supermercado a indenizar uma empregada doméstica afrodescendente acusada injustamente de furto. Fotografia de 2009. Página 26 do livro TERRITÓRIO E SOCIEDADE NO MUNDO GLOBALIZADO: ENSINO MÉDIO VOLUME 3 (2016).

A violência é fruto de um estado racista, e o livro também aponta isso, quando citam o mapa da violência. Tendo como principal objetivo levantar a violência letal, mais voltada à população jovem. O mapa da violência é uma proposta de atividade aos alunos, os instigando a pensar, analisar e entender logo em seguida o que o mapa quer dizer.

\begin{tabular}{|l|c|c|c|c|}
\multirow{2}{*}{ Regiāo } & \multicolumn{4}{|c|}{ Homicidios por armas de fogo } \\
\cline { 2 - 5 } & \multicolumn{3}{|c|}{ Branca número de homicidios com armas de fogo por raça/cor } \\
\cline { 2 - 5 } & 2003 & 2012 & 2003 & 2012 \\
\hline Norte & 277 & 385 & 1.370 & 3.433 \\
\hline Nordeste & 905 & 1.215 & 6.228 & 13.647 \\
\hline Sudeste & 8.530 & 4.346 & 10.516 & 7.824 \\
\hline Sul & 2.826 & 3.923 & 599 & 1.084 \\
\hline Centro-0este & 686 & 763 & 1.578 & 2.958 \\
\hline Brasil & 13.224 & 10.632 & 20.291 & 28.946 \\
\hline
\end{tabular}

Imagem 9: WAISELFISZ, Julio Jacobo. Mapa da Violência 2015: os novos padrões da violência homicida no Brasil. Brasília: Secretaria de Políticas de Promoção da Igualdade 
Racial. Página 29 do livro TERRITÓRIO E SOCIEDADE NO MUNDO GLOBALIZADO: ENSINO MÉDIO VOLUME 3 (2016).

\subsection{COTAS COMO AÇÕES AFIRMATIVAS}

Algo que é incrível e que o livro traz com muita leveza e naturalidade não diminuindo a importância do assunto é quando toca-se na vertente de cotas nas universidades públicas. Explica que é uma das mais polêmicas ações afirmativas mas que possui uma importância muito grande, inclusive explicando o seu objetivo final e que são necessárias para passar por cima das ‘'cotas invisíveis’’que já é uma realidade de espaços ocupados majoritariamente por brancos.

Traz também outras ações afirmativas, utilizando o exemplo da lei que foi aprovada em 2012 e tem 10 anos de duração que garante metade das vagas dos cursos nas universidades públicas e escolas técnicas para alunos da rede pública. Aponta como é importante ter paciência e que por mais que as cotas tragam um retorno quase que imediato em relação a ocupação, é uma ação afirmativa que demora tempo para ser avaliada, mas que tem sido extremamente importante para a mudança de cenário.

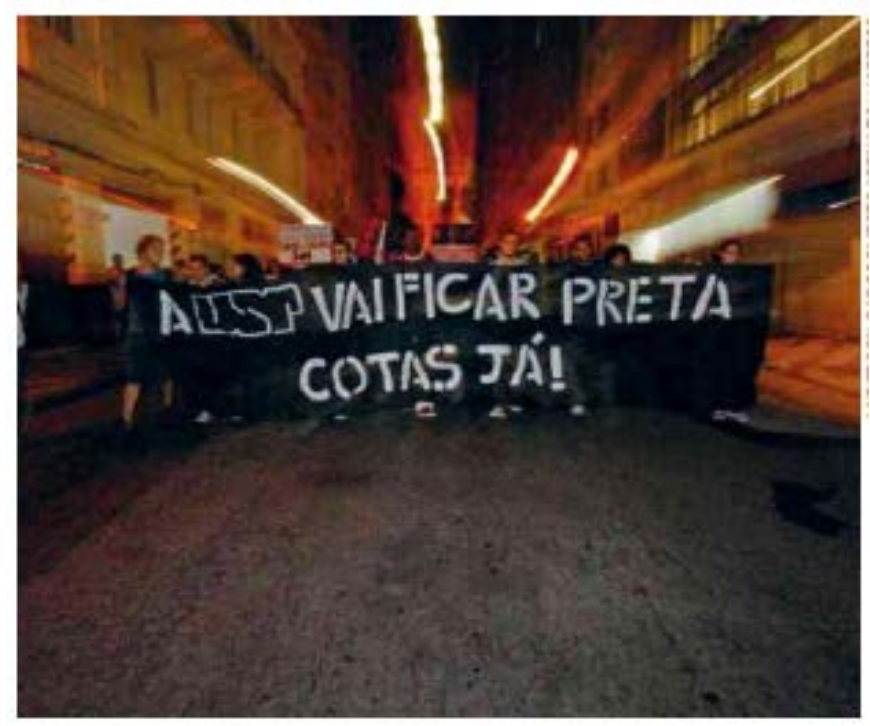

Imagem 10: Manifestação a favor das cotas em São Paulo (SP). Fotografias de 2012. Página 28 do livro TERRITÓRIO E SOCIEDADE NO MUNDO GLOBALIZADO: ENSINO MÉDIO VOLUME 3 (2016).

\section{3. COMUNIDADE QUILOMBOLA}

Foi retratado a comunidade quilombola no livro, primeiramente com muito respeito e sem estereótipo algum, contando a história e o porquê da existência desses espaços. Relata sobre a importância da constituição ter garantido o direito dessas terras e de permanência das 
mesmas, apesar de que nem todas recebem titulação. Para além de contar do histórico e da importância, o livro aborda a importância dos quilombolas na sociedade, apontando os desafios de manter a estruturação das práticas de exploração e desenvolvimento sustentável, manter os seus valores culturais e etc.

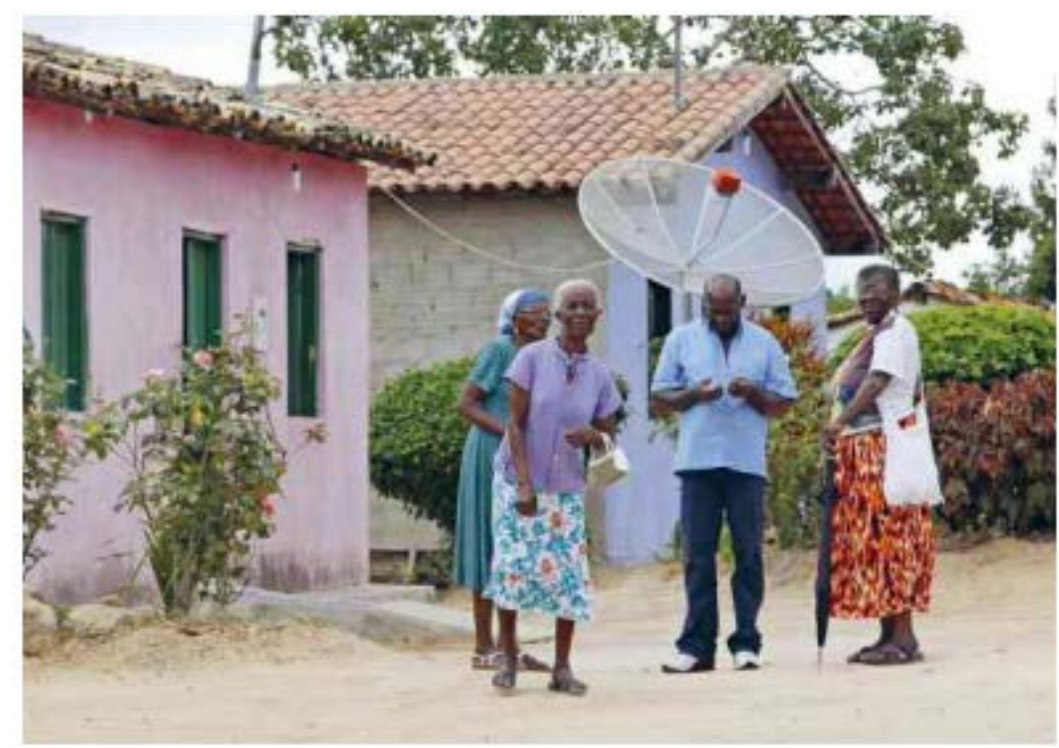

Imagem 11: Habitantes de Rio de Contas (BA) reúnem-se para a festa de São Sebastião na comunidade remanescente do Quilombo da Barra, em 2014. Página 28 do livro TERRITÓRIO E SOCIEDADE NO MUNDO GLOBALIZADO: ENSINO MÉDIO VOLUME 3 (2016).

\subsection{PROJETO RESPEITANDO AS DIFERENÇAS}

No final do livro, existem algumas proposta de aplicabilidade de atividades de todos os temas, e dentro do assunto dos afrodescendentes do Brasil, existem os conflitos religiosos e para isso foi criado o projeto 'respeitando as diferenças", tendo como objetivos: 1) Identificar elementos da sua identidade. 2) Reconhecer a diversidade étnica do povo brasileiro e valorizála. 3) Valorizar a sua identidade e reconhecer a do "outro”. 4) Identificar elementos culturais que ajudam a construir a identidade brasileira. O projeto é dividido em 3 etapas e são todas de extrema importância. Inclusive é um trabalho bem parecido ao que é desenvolvido na disciplina Geografia Afrobrasileira.

A primeira etapa consiste em pesquisar sobre a própria identidade, então os alunos precisam buscar quem são os seus ancestrais, montando uma árvore genealógica, dentro da pesquisa é necessário apontar se existe algum parentesco com grupos indígenas, afrodescendentes, europeus ou asiáticos; qual religião os parentes seguiram; quais hábitos 
tinham e quais desses se mantiveram; se já sofreram (ou sofrem) algum tipo de descriminalização por conta das suas origens.

A segunda etapa é para mapear as origens da turma, sendo em formato de vídeo, documentário, mapas e/ou preparar pratos típicos. A última e não menos importante etapa, é a promoção de um debate com a temática sobre preconceito e discriminação, dividindo a turma em grupos, e discutindo alguns pontos sendo eles:

- Quais são as principais causas para o preconceito e a discriminação?

- Seus antepassados sofreram algum tipo de preconceito ou intolerância em razão de sua origem?

- Vocês percebem, ainda nos dias de hoje, esses preconceitos e discriminações? Em que situações?

- Vocês já presenciaram ou foram alvo de algum tipo de discriminação por conta de suas origens, cultura ou modo de ser (local de nascimento, sotaque, religião, características físicas, classe social, opção sexual, entre outros)?

E logo após escolher um relator por grupo para que fale os principais pontos que foram discutidos e depois coletivamente debater sobre os seguintes pontos:

- Expliquem por que o Brasil pode ser considerado uma nação.

- Quais manifestações contribuem para a construção da identidade nacional?

- O que faz a turma se sentir pertencente à nação brasileira?

- Qual é a relação entre a diversidade cultural e os processos de globalização? Cite formas de como a globalização homogeneiza a identidade cultural e formas de como ela pode potencializar conflitos culturais diante da diversidade existente no mundo.

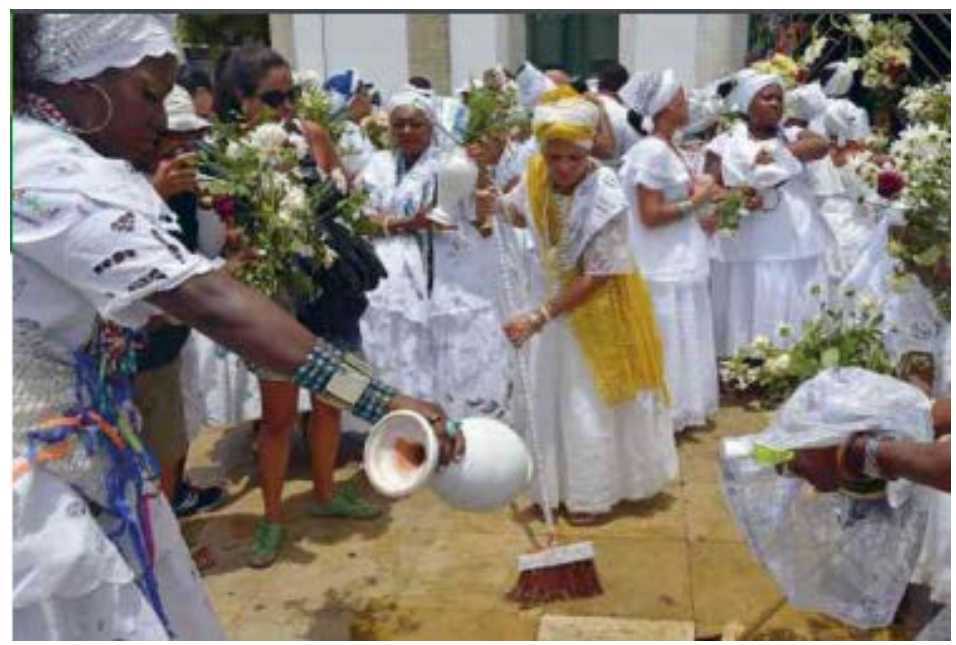

Imagem 12: A festa da lavagem do Bonfim, em Salvador (BA), que ocorre há mais de dois séculos, tornou-se um grande evento que une católicos e seguidores do 
candomblé. Essa união de crenças religiosas é conhecida como sincretismo religioso. Fotografia de 2014.

Página 220 do livro TERRITÓRIO E SOCIEDADE NO MUNDO GLOBALIZADO: ENSINO MÉDIO VOLUME 3 (2016).

\section{CONCLUSÕES E RECOMENDAÇÕES}

O presente livro de didático possui um diferencial em relação aos outros que foram analisados antes da escolha, começando pelo fato de ser um ótimo livro a ser usado, por abranger diversos assuntos em relação a população afrodescendente brasileira, em relação a áfrica e apresenta também ótimas atividades a serem desenvolvidas por meio do livro. Esse estudo permite abrir a mente e ter um visão ampla a respeito de como é tratado tal assunto nas escolas e de como novas abordagens podem ser apresentadas, aplicadas e aproveitadas em sala de aula.

Algo a ser destacado é o incentivo a busca por identidade e ancestralidade do livro para com os alunos, por meio de atividades e até mesmo leituras extras recomendadas. Além de ser um livro que possui diversas imagens, figuras didáticas, mapas e sugestões de filmes para além da sala de aula, que é exatamente assim que a educação começa a surtir um efeito maior na sociedade: quando é levado para fora. A utilização do espaço da sala de aula para abordar cada vez mais esses assuntos é de extrema importância, mas a criticidade sobre o material e a criatividade perante ele é algo indiscutível.

Por fim, a partir da análise do presente livro, as recomendações que surgem, especialmente para os docentes e gestores escolares, são:

- Desenvolver atividades extracurriculares para além do livro didático e do dia da consciência negra, utilizando a criatividade e a abundância de recursos atuais, tais como internet, netflix, instagram, tiktok e etc.

- Desenvolver debates sobre discriminação racial, desigualdades, preconceito e exclusão social por meio de construção de mapas e conhecimento de ancestralidade individual.

- Inserção do assunto como parte do plano político pedagógico das escolas como algo indispensável.

- Criação de projetos e oficinas que falem sobre o protagonismo negro na atualidade para aplicação bimestral, podendo até se converter e ser adaptada para ocupar a matéria de PD (Projeto Disciplinar) nas escolas, virando um projeto recorrente, visto que a lei 
10.639 de 2003 estabelece a obrigatoriedade do ensino de história da África e das culturas africana e afrobrasileiras, iniciando um projeto pedagógico e aplicando a lei.

\section{REFERÊNCIAS BIBLIOGRÁFICAS}

ALVES, L. A. CONTRIBUIÇÕES DA GEOGRAFIA ESCOLAR PARA A ABORDAGEM DA HISTÓRIA E CULTURA AFRO-BRASILEIRA E AFRICANA NO ENSINO FUNDAMENTAL II. Olhares \& Trilhas, v. 20, n. 1, p. 32-41, 28 abr. 2018.

AZEVEDO, Daniel Abreu de. Ensino de Geografia: Novos Temas Para A Geografia Escolar. [S. l.: s. n.], 2019.

LUCCI, Elian Alabi; BRANCO, Anselmo Lazaro \& MENDONÇA, Cláudio. TERRITÓRIO e SOCIEDADE NO MUNDO GLOBALIZADO: ENSINO MÉDIO - MANUAL DO PROFESSOR Volume 3. Terceira Edição. São Paulo: Editora Saraiva, 2016. 